\title{
Assessment of child psychomotor development in population groups as a positive health indicator
}

\author{
Horacio Lejarraga, M.D. ${ }^{a}$, Diana M. Kelmansky, M.D. ${ }^{a, b}$, María C. Passcucci, M.D. ${ }^{a}$, \\ Alicia Masautis, B.S. ${ }^{a}$,Iván Insua, M.D. ${ }^{a}$, Celina Lejarraga, M.D. ${ }^{a}$ and FernandoNunes M.D. ${ }^{c}$
}

\begin{abstract}
Introduction. It is necessary to use health indicators describing the conditions of all individuals in a population, not just of those who have a disease or die.

Objectives. To introduce a method to collect population indicators of psychomotor development in children younger than 6 years old and show its results.

Population and methods. Data were obtained from a cross-sectional assessment regarding compliance with 13 developmental milestones (selected from the national reference) conducted in 5465 children using five surveys administered by the Matanza-Riachuelo River Basin Authority in areas of this basin where a high proportion of families with unmet basic needs live. For each survey, a logistic regression analysis was used to estimate the median age at attainment of the 13 developmental milestones. A linear regression model between the estimated age at attainment of the 13 milestones was adjusted for each survey based on the corresponding age at attainment of the national reference. Based on this model, three indicators were defined: overall developmental quotient, developmental quotient at 4 years old, and developmental trend.
\end{abstract}

Results. Results from the five surveys ranged between 0.74 and $0.85,0.88$ and 0.81 , and -0.15 and -0.26 for the overall developmental quotient, developmental quotient at 4 years old, and developmental trend, respectively. A distinct developmental delay and an increasing trend in delay with age were observed.

Conclusions. Indicators are easily interpreted and related to social indicators (unmet basic needs, etc.). Collecting the information necessary to make estimations takes little time and can be applied to population groups, but not on an individual level.

Key words: growth and development, health indicators, public health, socioeconomic factors.

http://dx.doi.org/10.5546/aap.2016.eng.23

E-mail address:

Horacio Lejarraga, M.D.: cursotesis07@gmail.com

\section{Funding:}

Matanza-Riachuelo

River Basin Authority

(ACUMAR).

Conflict of interest:

None.

Received: 3-31-2015

Accepted: 9-8-2015 and a denominator that accounts for the exposed population. They have shown a sustained declining trend in Latin America and around the world. However, when infant mortality rate in Argentina is described to be $12 \%$, it refers to the 12 infants who die before turning one year old per 1000 live births, but no information is provided on the health condition of the 988 children who are included in the denominator and survive.

From the broad perspective of public health, we should ask ourselves what happens with children who do not die. In many countries, growth and development of these surviving children is inadequate. In relation to growth, decades ago James Tanner ${ }^{3}$ and Robert Fogel ${ }^{4}$ proposed using population groups $\mathrm{s}^{3,5}$ as a positive indicator. At present, anthropometrybased physical growth is used in the field of epidemiology worldwide, including Argentina.

Development is related to the realization of an individual's potential in society in areas such as intelligence, motor skills, language and learning. According to previous studies conducted in Argentina, many children are at risk of developmental delay, ${ }^{6}$ but, unlike growth, there is no simple and reliable method to measure growth in population groups. There are several screening or diagnostic tests available, but screening tests do not provide quantitative data, and the administration of diagnostic tests takes too much time, requires highlytrained staff and are too costly to be used as a public health indicator.

In the 2010-2014 period, the General Environmental Health Division of the Matanza-Riachuelo River Basin Authority (Autoridad de Cuenca Matanza Riachuelo, 
ACUMAR) assessed psychomotor development in 12000 children younger than 6 years old from population groups with a high level of unmet basic needs (UBNs) ${ }^{7}$ living in the Matanza Riachuelo River Basin (MRRB) and found an elevated prevalence of children with a high risk of developmental delay. 8,9

In this article, we describe the methods used to measure development in population groups intended for use as positive indicators of children development.

\section{POPULATION AND METHODS}

ACUMAR is an inter jurisdictional state agency (managed at a national, provincial and municipal level), established by Act 26 168/2006 in reference to the environmental degradation occurred in the MRRB. In 2008, the Argentinean Supreme Court of Justice required ACUMAR to implement a sanitation plan in response to a court case known as the "Mendoza lawsuit". In this scenario, ACUMAR articulates public policies and coordinates inter-agency efforts to implement the Emergency Health Plan, part of the Comprehensive Environmental Sanitation Plan, whose purpose is to generate protection processes that will minimize the impact of hazards on health among the most vulnerable populations, and to promote environmental recovery in an area with almost six million inhabitants and more than 600000 children younger than 6 years old. In this context, the General Health Division of ACUMAR conducted a series of health surveys, among other actions. $^{8}$

\section{Surveys and samples}

In the 2011-2014 period, several surveys were administered to populations with UBNs. ${ }^{7}$ The Study on Nutrition, Development and Toxicological Analysis II (Estudio de Nutrición, Desarrollo Psicomotor y Análisis Toxicológico II, ENUDPAT II) was implemented in impoverished areas of La Matanza (LM) and Florencio Varela (FV) (the latter is not part of the MRRB but it was included for the purpose of comparing child development in both areas). Sample definition was based on census data obtained in the most recent National Population, Households and Housing Census, conducted in 2010. Populations whose census tracts had a percentage of UBNs equal to or higher than the mean percentage for the entire MRRB, which was estimated at $23.48 \%$, were included. Samples were selected in a probabilistic fashion. Each home was defined as the sampling unit; once census tracts were selected (a total of 40 ), secondary units were established (blocks) and, subsequently, units with at least 30 children younger than 6 years old each were selected. The sample size was 1025 children in LM and 1199 children in FV.

The other four surveys conducted in the MRRB were administered to the overall population of children younger than 6 years old in each selected area: Wilde (698 children), Acuba (1037 children), Villa Inflamable (628 children), and Villa 21-24 (958 children). After social workers visited each home to explain the study and encourage people to participate, parents signed an informed consent, and the technical team collected information on socio-demography, anthropometry, toxicology and nutrition, together with qualitative data (childrearing and risk perception), and administered a test on inapparent developmental disorders using the National Screening Test (Prueba Nacional de Pesquisa, PRUNAPE). ${ }^{10}$ Four to eight children were excluded from each area due to known chronic diseases. ${ }^{8,9}$

\section{Positive indicator}

For the purpose of using development as a positive indicator, survey takers were trained to assess attainment of 13 developmental milestones, which were selected from a total of 79 milestones available at the national reference (NR) $)^{11,12}$ (median age at attainment is shown in days old between parentheses): social smile (33), looks for his / her mother with the eyes (142), head control (33), looks for an object (226), pincer grasp (277), walks on his/her own (376), daytime bladder and bowel control (767), combines words (693), utters complete sentences (829), recognizes three colors (1209), walks heel-toe (1318), copies a cross (1340), draws a person with 6 parts (1534). Milestones are tests to be complied with, except for the last three, which are asked to parents. These milestones are attained at different ages, so each child has to complete between 4 and 7 milestones, which takes just a few minutes. These milestones were chosen to cover the main areas of development and had been selected in a previous study. ${ }^{13}$

For each survey, a logistic regression model ${ }^{14}$ was used to estimate the $50^{\text {th }}$ percentile (median) of age (in days old) at attainment of each of these 13 milestones; data adjustment was observed to be adequate, except for two milestones in Acuba, which were not included in the subsequent analysis of this area. 
Studied areas showed a high linear association in the differences (" $y$ ") between median age at attainment of each milestone in the sample and the corresponding median age as per the NR. Therefore, a scatter plot of the differences (" $y$ ") and the corresponding age in the NR (" $x$ ") was done for each area, and a least square straight line (adjusted to the plot's pairs of dots) and each resulting equation were adjusted using the following formula: $y=a+b . x$. In the formula, " $y$ " is the difference between median age at attainment of milestones among children from the studied area and median age at attainment of milestones as per the NR; "a" is the origin of the straight line when " $x$ " equals 0 (zero); " $x$ " is the age at attainment of milestones according to the NR.

In all areas, straight lines showed a declining trend (Figure 2). An older age in the NR was associated with an increasingly older age at attainment of milestones. Such trend is quantified by the " $b$ " slope, which corresponds to the delay in days for each day that the age in the NR increases. Theoretically, if no developmental delay was recorded in an area, the slope would be null; if a developmental delay was observed to increase with age, the slope would be negative, as observed in all studied areas.

In order to summarize development in a population, the following were proposed:

Overall developmental quotient (ODQ), obtained based on the "b" slope:

$\mathrm{ODQ}=1+\mathrm{b}$

Example: for area A, the slope of the straight line is -0.1476957 (rounded off to -0.15). The equation would be as follows:

$\mathrm{ODQ}=1+(-0.15)=0.85$

This means that overall development of children in this area is $85 \%$ from the NR, i.e., they attain developmental milestones at an age that is $15 \%$ later than that of children in the NR (1$0.85)$. If expressed as a percentage, it would be ODQ $=100 \times 0.85=85 \%$.

Knowing the "a" and " $b$ " coefficients of the adjusted straight line $(y=a+b . x)$, it is possible to estimate the developmental quotient at any age. For example, at 4.0 years old:

$\mathrm{x}=4.0 \times 365=1460$ days old

Remember that in the straight line equation, " $y$ " corresponds to differences. Following with the example for area $\mathrm{A}$, where the equation of the straight line is $y=41.1-0.15 . x$, then at 1460 days old (" $x$ "), the difference " $y$ " $=41.1$ $0.15 .1460=-177.9$ (rounded off to 178); with these values, developmental quotient (DQ) at 4 years old is estimated as follows:

DQ4 $=[1460+(-178)] / 1460=1282 / 1460)=0.88$

If the overall developmental quotient at 4 years old is 0.88 , milestones which are attained at a median age of 4.0 years old as per the NR are attained by $88 \%$ of children in the sample for that age; $12 \%$ (100 - 88) have a delay. Approximations are made only to describe estimations.

Developmental trend (DT): It indicates the change in differences between median age at attainment of milestones in the sample and as per the NR, as age increases, and is directly the " $\mathrm{b}$ " coefficient of the adjusted straight line. In the example for area A, DT is -0.15 ; this means that a child has a delay (negative result) of 0.15 days for each day passed in the age at attainment of milestones in relation to the NR.

\section{RESULTS}

Table 1 shows the number of studied children in each area. We included the percentage of children who fail the PRUNAPE ${ }^{11}$ in the areas studied here and in other previous studies. ${ }^{15,16}$ The prevalence of children who fail the PRUNAPE increases with age and reaches its peak at 4 years old, but then undergoes a dramatic drop (between 5.0 and 5.99 years old).

Figure 1 shows how age at attainment of each milestone was estimated for each area. There is an adequate adjustment of logistic regression to crude data.

Having estimated the median age for each milestone in each survey, we calculated differences (" $y$ ") between these ages and those corresponding to the NR. Next, linear regressions were adjusted using " $y$ " (differences with age as per the NR) and " $x$ " (age at attainment of each milestone as per the NR). Figure 2 shows the results of the five areas. For confidentiality reasons, a letter was assigned to each area.

During the first three months of life, there are no remarkable differences between studied infants and the NR; however, as of 700-750 days old, differences increase at a consistent rate, suggesting a progressive delay in all studied areas. For example, children in area A start showing a delay at a rate of 0.15 days per day.

Table 2 shows the three proposed indicators, together with some social indicators.

We estimated DQ at 4 years old and not at a different age because, according to all previously conducted studies, the prevalence of children with a risk of developmental delay is higher at this age. 
All developmental indicators show a varying degree of delay (lower than 1.0) and show consistency among one another. At 4 years old, children from area $\mathrm{A}$ and $\mathrm{C}$ show the lesser and greater delay, respectively, with a DQ of 0.88 and 0.81 . These quotients are consistent with ODQs. The areas with a higher percentage of families with UBNs are those with a lower ODQ. In area A, the rate of delay was -0.15 days per day, a trend that is much more marked in area $C$, with a DT of -0.26 days per day. ODQ values are also consistent with the remaining indicators. Data included in the table depict a highly adverse environment.

Available anthropometric information ${ }^{8,9}$ shows prevalence values of children with wasting (body mass index [BMI] or weight/height) and stunting (height/age) ranging between 0.3 and $1.2 \%$ and between 2.2 and $3.7 \%$, respectively, which are within the expected proportion in a normal population for the cut-off value and
FIGURE 1. Regression equation adjusted to data for milestone 10 in Wilde

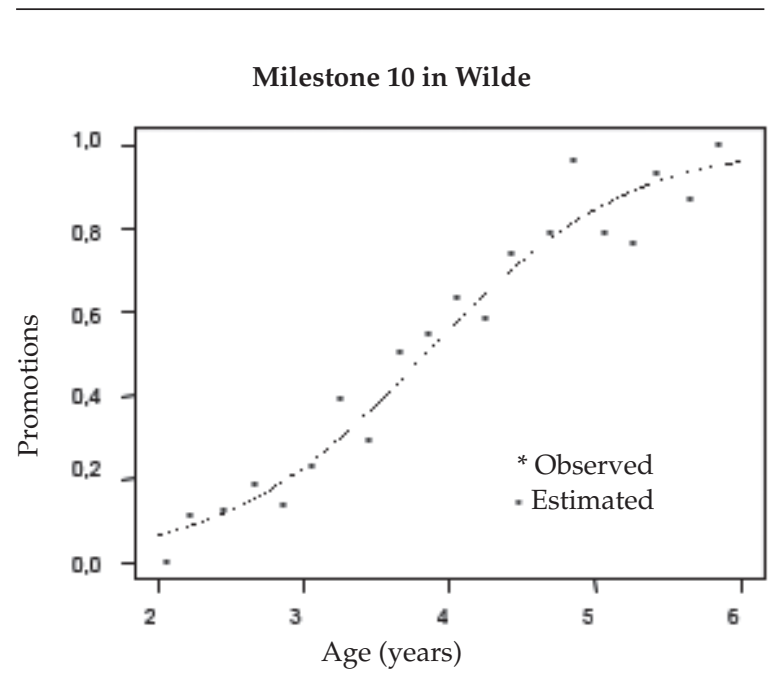

Milestone 10 is "recognizes three colors". Each star in the plot accounts for the proportion of children who attain one milestone in each age range.

TABLE 1. Total number of children studied in each area, percentage of children who fail the PRUNAPE National Screening test, by age group in different surveys and areas

\begin{tabular}{lccccccc}
\hline Age range & Area A & Area B & Area C & Area D & Area E & Boulogne* $^{*}$ Martínez $^{*}$ \\
\hline $0-9.99$ & $319(14.7)$ & $105(5.5)$ & $77(28.6)$ & $149(10.7)$ & $118(11.1)$ & $97(4.0)$ & $29(3.4)$ \\
$1-1.99$ & $334(25.4)$ & $125(10.4)$ & $128(35.2)$ & $165(13.3)$ & $51(21.6)$ & $97(6.1)$ & $35(2.9)$ \\
$2-2.99$ & $324(35.5)$ & $114(17.5)$ & $122(48.4)$ & $165(29.1)$ & $36(27.8)$ & $60(33.3)$ & $20(15.0)$ \\
$3-3.99$ & $324(47.8)$ & $107(28.0)$ & $86(53.5)$ & $164(32.3)$ & $30(60.0)$ & $55(30.9)$ & $27(37.0)$ \\
$4-4.99$ & $291(54.3)$ & $118(24.5)$ & $87(55.2)$ & $139(40.0)$ & $38(50.0)$ & $50(40.0)$ & $19(31.9)$ \\
$5-5.99$ & $291(33.3)$ & $97(16.4)$ & $79(38.0)$ & $111(19.8)$ & $27(40.7)$ & $38(26.3)$ & $12(8.3)$ \\
Total & 1893 & 666 & 579 & 893 & 300 & 397 & 142 \\
\hline
\end{tabular}

* Reference 17 (Boulogne and Martínez, San Isidro, Province of Buenos Aires).

TABLE 2. Developmental quotient at 4 years old, overall developmental quotient, regression coefficients (developmental trend) and $95 \%$ confidence intervals for the five areas and social indicators

\begin{tabular}{lcccccc}
\hline Area & ODQ & DT (days/day) & DQ4 & \% UBNs & \% PME & \% with no RW \\
\hline A & $0.86(0.82 ; 0.91)$ & $-0.15(-0.20 ; 0.10)$ & $0.88(0.87 ; 0.89)$ & 64.7 & 12.7 & 23.5 \\
B & $0.82(0.79 ; 0.86)$ & $-0.19(-0.24 ;-0.15)$ & $0.83(0.82 ; 0.85)$ & $76.8 / 80.3^{*}$ & 11.7 & 34.3 \\
C & $0.77(0.70 ; 0.85)$ & $-0.26(-0.35 ;-0.16)$ & $0.81(0.78 ; 0.83)$ & 81.3 & 14.4 & 41.8 \\
D & $0.85(0.80 ; 0.90)$ & $-0.16(-0.22 ;-0.10)$ & $0.85(0.80 ; 0.90)$ & 67.0 & 26.3 & 11.2 \\
E & $0.85(0.79 ; 0.91)$ & $-0.17(-0.23 ;-0.10)$ & $0.84(0.82 ; 86.7)$ & 90.0 & 13.5 & 47.8 \\
\hline
\end{tabular}

* Area B includes two different communities with unmet basic needs (UBNs) but with the same developmental indicators. ODQ: Overall developmental quotient.

DT: Developmental trend.

DQ4: Developmental quotient at 4 years old.

$\%$ UBNs: Percentage of unmet basic needs.

$\%$ PME: Percentage of mothers with incomplete primary education.

$\%$ with no RW: Percentage of homes with no running water 
references used (-2.0 SD as per the World Health Organization [WHO] standards). ${ }^{15}$

\section{DISCUSSION}

In this article, we propose using psychomotor development as a positive indicator of health; we describe a method to measure psychomotor development using cross-sectional data and provide results from several surveys administered to social groups with UBNs. The method is based on a regression model where age at attainment of the sample milestones is compared to that indicated as per the NR, and is used to measure development in population groups, not at an individual level, given that data are obtained by assessing whether children attain the milestone or not. Several indicators are built based on the regression model. ODQ expresses the group's overall development, as a quotient or percentage of age in relation to the NR. DT indicates changes over time in age at attainment compared to the NR, and DQ4 describes developmental quotient at 4 years old (age at which developmental delay is more distinct), but it may be estimated for any age. DQ4 may be considered comparable to mean height in a

FiguRE 2. Differences (" $y$ ") between median age at attainment observed in the surveys and median age as per the national reference, plotted against (" $x$ ") median age as per the national reference and linear regression equations for each data group

Median age of 13 milestones in $\mathrm{A}$

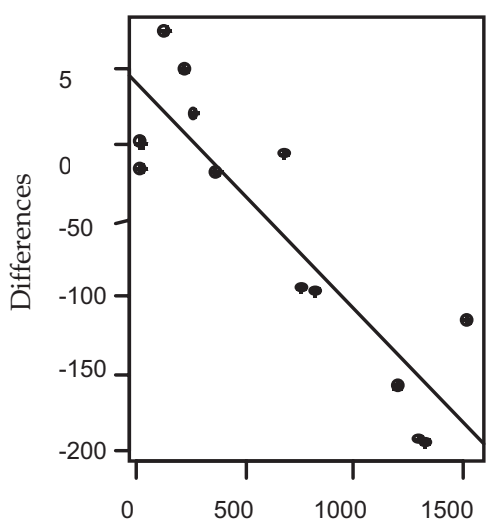

Age as per national reference $\mathrm{y}=41,1-0,50 \mathrm{x}$

Median age of 11 milestones in D

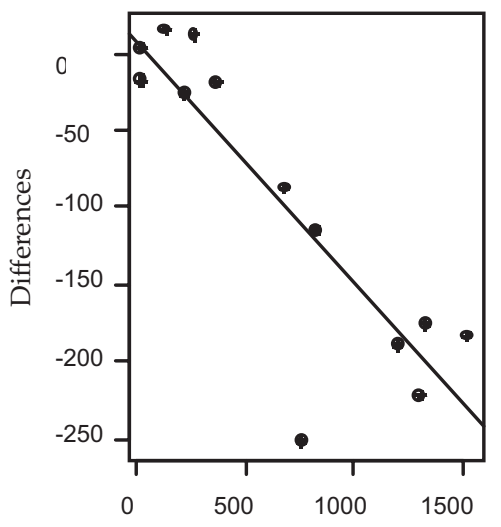

Age as per national reference $\mathrm{y}=9,0-0,16 \mathrm{x}$
Median age of 13 milestones in B

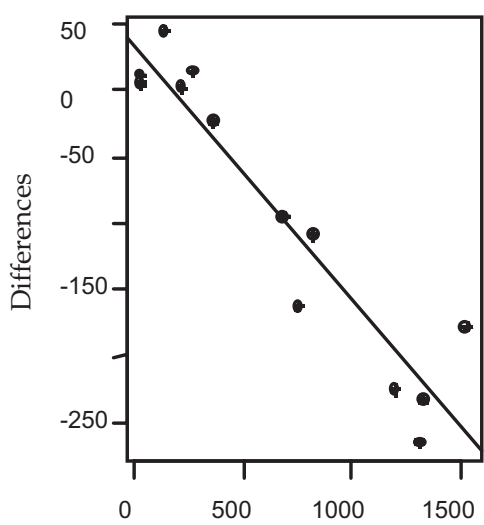

Age as per national reference $\mathrm{y}=35,1-0,19 \mathrm{x}$

Median age of 11 milestones in E

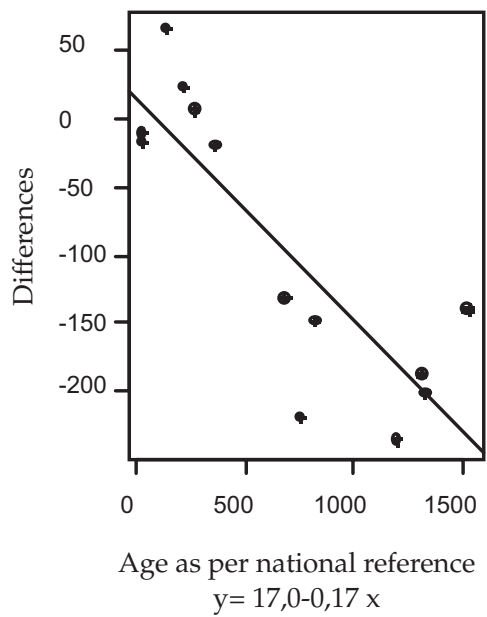

Median age of 11 milestones in C

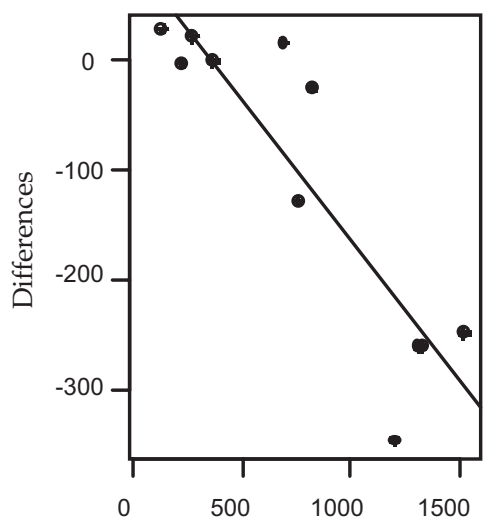

Age as per national reference $y=92,2-0,26 x$

Each letter (A-E) refers to one of the five studied areas. 
group of children at 4 years old compared to that indicated in a growth chart.

Results show an important delay in children living in disadvantaged areas from the MRRB, as described in other studies. ${ }^{17-19}$ Developmental delay is not observed in the first year of life, which has also been described in Argentina and other countries; ${ }^{18,19}$ however, it occurs around 1.5 years old and increases with age. The rate of such deterioration may be measured using the second indicator: DT.

This method assumes that, at birth (age zero), the studied group has no developmental delay, which is consistent with all population studies conducted worldwide.

The age at which children attain developmental milestones varies from one country to another. At 1 year old, the milestone "walks on his/her own" is similar in different countries, ${ }^{20}$ but differences were observed in milestones attained at an older age. For example, median age at attainment of the milestone "copies a cross" is 3.7, 3.2 y 3.67 years old in Colorado, ${ }^{21}$ Northern China ${ }^{22}$ and Argentina, respectively. ${ }^{12}$ Such differences may be related to childrearing, secular changes, etc. For this reason, the $\mathrm{WHO}$ recommends that each country uses its own developmental parameters as reference. ${ }^{23}$ The Bayley-I scale was standardized in 1960, ${ }^{24}$ the Denver-II test, in $1988 ;{ }^{25}$ and the Chilean test, in $1974,{ }^{26}$ all in very different times. Also, it is known that median ages may vary over time, as observed in certain items of the 1980 Griffiths scale compared to the 1970 version. ${ }^{27}$

One of the conditions of our proposed method is that the entire group of children included in the program should be assessed, or at least a sample, in order to accurately comply with one of the properties of a "positive health indicator". To this end, we prefer using information obtained from the healthcare process itself. A few developmental milestones measured by duly-trained healthcare agents and collected during regular health checkups may provide valuable, consistent and comparable information, provided that attainment is assessed as per the same criteria. Selected milestones comprise different areas of development (fine and gross motor skills, cognition, language, personal-social); they are related to social variables and show a great level of consistency among results. They may be replaced with other or a larger number of milestones; this would reduce confidence intervals of indicators, but their administration would take more time. The proposed method is practical, accurate and low-cost, it also offers reliable and understandable information and is described in relation to a reference population, as also occurs with growth data. This method may be used to monitor interventions and also provides dynamic information on developmental trends (delay or, eventually, advance) in children over the $0-5$ year-old period.

Children development refers to the course of changes in sensory-motor skills, emotional response, intelligence, language and learning. ${ }^{28}$ Development is related to a child's realization of potentials and performance as an adult; any disorder may lead to disability and have an impact on an individual's dignity. Measuring development is relevant, especially in the critical and vulnerable period of 0 to 5 years old. Other investigators consider it necessary to use new indicators for health determinants, ${ }^{29}$ but such need also extends to health outcomes. ${ }^{5}$ In the $21^{\text {st }}$ century, reducing infant mortality cannot be the only goal pursued by health programs; we should also promote a positive growth and development in children, and for this reason, we require adequate indicators.

\section{Acknowledgments}

We would like to thank Graciela Blatt for her help and logistic support with all our studies.

\section{REFERENCES}

1. World Health Organization. World Health Statistics 2014. A wealth of information on global public health. Geneva: World Health Organization; 2014.

2. Sociedad Argentina de Pediatría, UNICEF. Salud materno-infanto-juvenil en cifras. 2013. Buenos Aires: UNICEF; 2013.

3. Tanner JM. Growth as a mirror of the condition of society; secular trends, and class distinctions. In: Dubuc MB, Demirdjian A, eds. Human growth: a multidisciplinary review. London: Taylor and Francis; 1986. Pages 3-34.

4. Fogel RW. Anthropometric history: notes on the first two decades of a new field of research. In: Hauspie R, Lindgren G, Falkner F, eds. Essays of auxology: presented to James Mourilyan Tanner by former colleges and fellows. Welwyn Garden City: Castlemead; 1995. Pages 271-84.

5. Schlaepfer-Pedrazzini L, Infante-Castañeda C. La medición de la salud: perspectivas teóricas y metodológicas. Salud Pública Mex 1990;32(2):141-55.

6. Lejarraga H, Meletti I, Biocca S, Alonso V. Secular trend and environmental influences on growth at adolescence in Argentina. In: Tanner JM, ed. Auxology 88: Perspectives in the science of growth and development. London: Smith- Gordon; 1989. Pages 211-20.

7. Instituto Nacional de Estadísticas y Censos. Necesidades Básicas Insatisfechas. BuenosAires, 2010. [Accessed on: September 8, 2015]. Available at:http://www.indec.gov. ar/nivel4_default.asp?id_tema_1=4\&id_tema_2 $=27 \& i d$ _ tema_3 $=66$. 
8. Autoridad Cuenca Matanza Riachuelo (Acumar). Informes de la Dirección General de Salud Ambiental. Argentina, 2014. [Accessed on: September 14, 2015]. Available at: www.acumar.gov.ar

9. Lejarraga H, Pascucci MC, Masautis A, Kelmansky D, et al. Desarrollo psicomotor infantil en la cuenca MatanzaRiachuelo: pesquisa de problemas inaparentes del desarrollo. Rev Argent Salud Pública 2014;19(5):17-24.

10. Lejarraga H, Kelmansky D, Pascucci MC, Salamanco G. Prueba Nacional de Pesquisa PRUNAPE. $2^{\text {da }}$ ed. Buenos Aires: Fundación Hospital Garrahan; 2006.

11. Lejarraga H, Krupitzky S, Giménez E, Diament N, et al. The organisation of a national survey for evaluating child psychomotor development in Argentina. Paediatr Perinat Epidemiol 1997;11(3):359-73.

12. Lejarraga H, Krupitzky S, Kelmansky D, Martínez E, et al. Edad de cumplimiento de pautas de desarrollo en niños argentinos sanos menores de seis años. Arch Argent Pediatr 1996;94(6):355-68.

13. Lejarraga H, Pascucci MC, Krupitzky S, Kelmansky D, et al. Psychomotor development in Argentinean children aged 0-5 years. Paediatr Perinat Epidemiol 2002;16(1):47-60.

14. Hosmer DW, Lemeshow S. Applied logistic regression. New York: Wiley; 1989.

15. WHO Multicentre Growth Reference Study Group. WHO Child Growth Standards based on length/height, weight and age. Acta Paediatr Suppl 2006;450:76-85.

16. Lejarraga H, Menéndez AM, Menzano E, Guerra L, et al. Screening for developmental problems at primary care level: a field programme in San Isidro, Argentina. Paediatr Perinat Epidemiol 2008;22(2):180-7.

17. Lejarraga H, Menéndez AM, Menzano E, Guerra L, et al. PRUNAPE: pesquisa de trastornos del desarrollo psicomotor en el primer nivel de atención. Arch Argent Pediatr 2008;106(2):119-25.

18. Sameroff AJ. Environmental risk factors in infancy. Pediatrics 1998;102(5 Suppl E):1287-92.
19. Super CM. Environmental effects on motor development: the case of "African Infant precocity". Dev Med Child Neurol 1976;18(5):561-7.

20. WHO Multicentre Growth Reference Study Group. WHO Motor DevelopmentStudy: windows of achievement for six gross motor development milestones. Acta Paediatr Suppl 2006;450:86-95.

21. Frankenburg WK, Dodds J, Archer P, BresnickB, et al. Denver II training manual. 2nd ed. Denver: Denver Developmental Materials; 1992.

22. Restandarization of DDST from six cities in north China. The Collaborative Group of Child Developmental Test. Chin Med J (Engl) 1986;99(2):166-72.

23. Lansdown RG, Goldstein H, Shah PM, Orley JH, et al. Culturally appropriate measures for monitoring child development at family and community level: a WHO collaborative study. Bull World Health Organ 1996;74(3):283-90.

24. Bayley N. BSDI. Escalas Bayley de desarrollo infantil. Manual. Madrid: TEA; 1977.

25. Frankemburg WK, Dodds J, Archer P, Shapiro H, et al. The Denver II: a major revision and restandardization of the Denver Developmental Screening Test. Pediatrics 1992;89(1):91-

26. Rodríguez S, Arancibia V, Undurraga C. Escalade evaluación del desarrollo psicomotor de 0 a 24 meses. Santiago de Chile: Galdoc; 1974.

27. Nordberg L, Rydelius PA, Zetterström R. Psychomotor and mental development from birth to age of four years; sex differences and their relation to home environment. Children in a new Stockholm suburb. Results from a longitudinal prospective study starting at the beginning of pregnancy. Acta Paediatr Scand Suppl 1991;378:1-25.

28. Lejarraga H. Desarrollo del niño en contexto. Buenos Aires: Paidós; 2006.

29. Kruize H, Droomers M, Van Kamp I, Ruijsbroek A. What causes environmental inequalities and related health effects? An analysis of evolving concepts. Int J Environ Res Public Health 2014;11(6):5807-27. 